Journal of Computer Science 7 (12): 1846-1853, 2011

ISSN 1549-3636

(C) 2011 Science Publications

\title{
Development of an Algorithm for Fiber-to-the-Home Passive Optical Network Automatic Self-restoration Scheme Using Access Control System
}

\author{
${ }^{1-2}$ Mohammad Syuhaimi Ab-Rahman and ${ }^{1}$ Siti Raihan Ahmad Mahir \\ ${ }^{1}$ Spectrum Technology Research Group (SPECTECH), Malaysia \\ Department of Electrical, Electronics and Systems Engineering, \\ Faculty of Engineering and Built Environment, \\ ${ }^{2}$ Institute of Space Science (ANGKASA), \\ University Kebangsaan Malaysia, 43600 UKM Bangi, Selangor, Malaysia
}

\begin{abstract}
Problem statement: Cables that are installed outdoors are subjected to harsh environmental conditions which make break down inevitable. When this happen it will disrupt the services and cause trouble to the users. To overcome this is to provide a means of restoring the network in case of failure. We introduced the Access Control System (ACS) and Customer Access Protection Unit (CAPU) to provide FTTH-PON monitoring, fault detection and protection. Approach: To design the C programs for ACS and CAPU, we will come up with the algorithms which describe the switching configuration in general. The switching configurations are tabulated in truth tables and flow charts are constructed. Based on the flow charts, the respective C programs for ACS and CAPU will be written. The C programs will then be tested through simulation. After successful simulations, the programs will be downloaded into the respective PIC microcontrollers in the ACS and CAPU for lab testing. Results: When several faults occur at various lines, each Multi Access Detection System (MADS) informs ACS and all CAPUs of the current line conditions. As programmed, ACS and CAPU will configure their switches to restore the network. When one of the working lines fail, the optical signal will be routed to its dedicated protection line. But when both its working and protection line fail, the optical signal will be routed to its neighboring protection line. Conclusion: We have successfully simulated the restoration of the optical signal when fault occur at its working line by restoring it to its dedicated protection line.
\end{abstract}

Key words: Access Control System (ACS), Customer Access Protection Unit (CAPU), Multi Access Detection System (MADS), Optical Line Terminal (OLT), Media Access Control (MAC), Smart Access Network-Testing Analyzing and Database (SANTAD),

\section{INTRODUCTION}

Fiber-To-The-x (FTTx, where ' $\mathrm{x}$ ' can be home, building and the like) has become the ultimate broadband access technology, outclassing copper cables (Digital Subscriber Lines) and coaxial cables (cable modems) (Hutcheson, 2008) (Yuksel et al., 2008). The increasing demand for advanced multimedia services (e.g., high definition television), corporate broadband applications (e.g., videoconferencing), high-speed internet access and many others has become the key driver for the deployment of FTTx (Hutcheson, 2008), (Lee et al., 2006). Copper cables and coax cables cannot cater for huge capacity demands and hence the superior FTTx becomes the ideal candidate to fulfill these demands (Hutcheson, 2008). Optical fiber cables are lighter in weight, can support greater bandwidth and can cover greater distances compared to copper and coax due to fiber's low attenuation per kilometer (Fijnvandraat and Bouwman, 2006). On the negative side however, the installation and maintenance of fiber cables are complex and costly (Fijnvandraat and Bouwman, 2006).

\section{MATERIAS AND METHODS}

Fiber optic cables are installed outdoors and thus they are exposed to ever-changing environmental conditions-temperature, moisture, dust particles and so on. Continuous exposure to harsh conditions may

Corresponding Author: Mohammad Syuhaimi Ab-Rahman, Spectrum Technology Research Group (SPECTECH), Department of Electrical, Electronics and Systems Engineering Faculty of Engineering and Built Environment, Malaysia 
adversely affect the cable. In turn, damage to fiber cables may upset any communications through the affected cables, rendering services unavailable. This, of course, will cause trouble to users who need to use network services. Therefore, there is a serious need to protect the cables from failures.

An FTTH access network failure due to fibber break in current optical communication system is making a challenge to the service providers to restore the system back to normal. According to the cases reported, the real advantage of FTTH PON is the fact that they use purely optical passive components that can withstand severe and demanding outside plant environment conditions without the need to consumer energy between in the central office exchange and the customer premises.

The occurrence of fiber faults is imminent. Typically, the telecommunication operators or solution providers would face major problems locating the faulty cable and the break point along the optical cable and also to restore their system back to normal (AbRahman et al., 2009c). Hence, the best possible option to overcome this problem is to provide a means of restoring the network in case of failure. A simple and effective monitoring configuration is highly desirable for timely failure detection along the fiber link. A good fault surveillance system is essential to identify the fiber fault without interrupting the services, while other channels are still in service to maximize the link utilization. A lot of research has been done in this regard and many protection architectures have been proposed. For example, (Nadarajah et al., 2006) proposed an Automatic Protection Switching (APS) scheme which involves the duplication of fiber cables and equipments in the Remote Node (RN). In this architecture, the channels which are affected by failure will be routed to predetermined routes. On the other hand, Yeh et al. (2008) proposed a duplex fiber system in which the Media Access Control (MAC) of each ONU activates optical switches for routing the optical signal to a backup line in case of failure.

In regard to FTTH-PON protection, we introduced the Access Control System (ACS). ACS is a new concept prototype device which operates in conjunction with other prototype devices such as Smart Access Network-Testing Analyzing and Database (SANTAD), Multi Access Detection System (MADS) and Customer Access Protection Unit (CAPU) to provide FTTH-PON monitoring, fault detection and protection. In this study, we will focus only on the protection system provided by ACS and CAPU, particularly the development of the algorithms which describe the self-restoration scheme. These algorithms became the basis for the development of two C programs which will dictate the operation of the ACS and CAPU respectively in accomplishing the automatic network self-restoration function. CAPU is included in smart FTTH network to perform as fast and smart restoration against failure in distribution region (Aziz et al., 2009).

Architecture of the FTTH-PON protection system using ACS: The ACS is installed between the Optical Line Terminal (OLT) and the ONU in the middle of a PON (Ab-Rahman et al., 2009a). The ACS is located after the passive node, as shown in Fig. 1. The ACS consists of a set of optical switches which are used for the routing of optical signals. These switches are controlled by a PIC microcontroller (Premadi et al., 2009a; 2009b). A single MADS device is installed on each working line and protection line for the detection of any occurrences of faults in the line. At the ONU end of the network, a line back to the transmission line ( $\mathrm{Ng}$ et al., 2010) CAPU is installed before each ONU. Each CAPU consists of a pair of optical switches which are controlled by a PIC microcontroller (Ab-Rahman et al., 2009b). CAPU optical switches are configured according to their ACS counterparts. While the ACS switches route the optical signal from the transmission line to either the primary line or a secondary (backup) line, the CAPU switches route the signal from the primary line or the secondary 2009).

Figure 2 shows the details of the self-restoration scheme architecture. At the output of the optical splitter, the single feeder fiber is split into a number of lines, called drop fibers. The number of drop fibers depends on the size of the optical splitter, usually $1 \times 32$. Other smaller or larger sizes are also available, such as $1 \times 16,1 \times 64$ and so on. Each drop fiber (which we also refer to as "traffic line" or "transmission line") is then split into a pair of linesa working line and a protection line by a pair of optical switches. Under normal conditions, the working line is used to carry the traffic signal while the protection line remains idle. In case the working line fails, the traffic signal will be routed to its dedicated protection line by means of the optical switches. However, if this protection line also fails, then the traffic signal will be routed to a neighboring protection line. Such protection architecture is known as the 1:1 non-dedicated protection architecture (Ab-Rahman 2009a). 


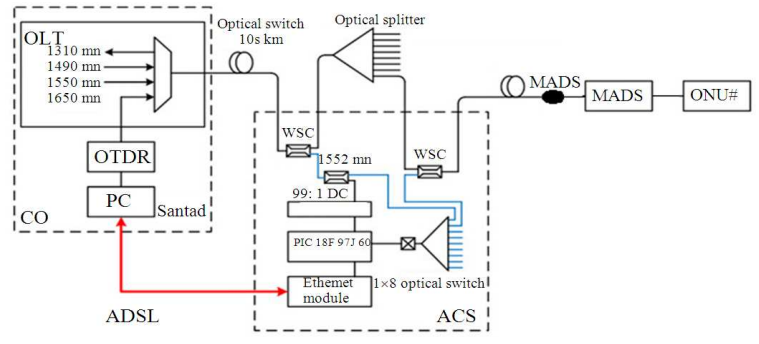

Fig. 1: The application of ACS in FTTH-PON

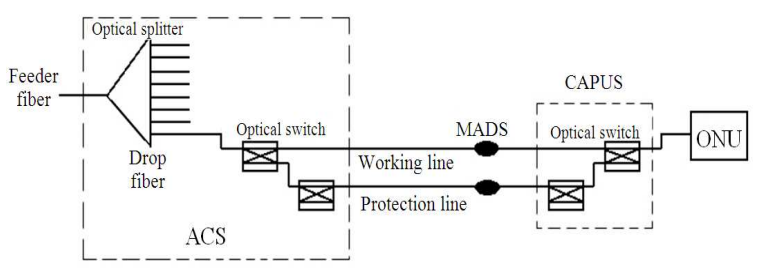

Fig. 2: The architecture of FTTH-PON selfrestoration scheme using ACS

The self-restoration scheme operates as follows: MADS periodically informs ACS as well as CAPU about the conditions of the transmission lines. MADS is responsible for updating ACS and CAPU regarding the condition of the line, whether it is functional or otherwise. Upon receiving information on the line conditions from MADS, the ACS and CAPU will configure their switches accordingly (Lee et al., 2006). The configuration of the switches determines the route of the traffic signals.

The automatic self-restoration scheme: This study will firstly explain the basis of the automatic selfrestoration scheme and then discuss the process of developing the algorithm of the self-restoration scheme.

Automatic self-restoration scheme concept: The first step in designing the switching algorithm for the selfrestoration scheme is to consider the possible line conditions and the flow of traffic signal for each of the conditions. Basically we have four different line conditions as follows:

First case: Normal condition: In the normal condition, the working line is functioning properly. By default, the working line will be used to carry the traffic signal. All the optical switches remain in their normal ('bar') state. The normal condition is illustrated in Fig. 3(a).

Second case: Level 1 breakdown: In this particular case, the working line W1 fails whereas its dedicated protection line P1 is still functional, as shown in Fig. 3(b). Thus, the traffic signal will be diverted to P1.

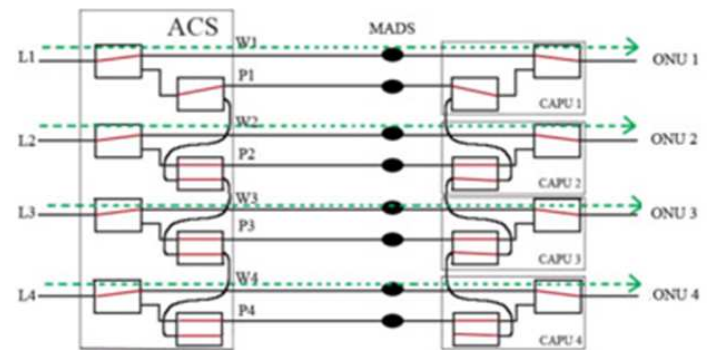

(a)

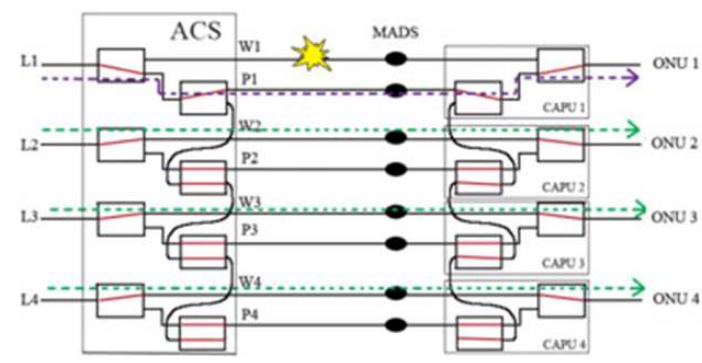

(b)

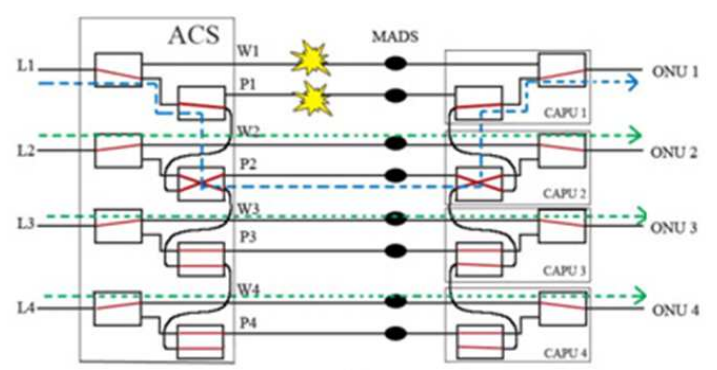

(c)

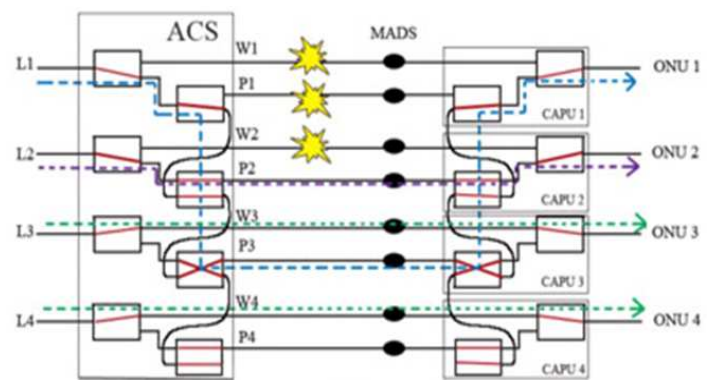

(d)

Fig. 3: Four different line conditions

ACS will activate its $1 \times 2$ switch to divert the traffic signal to the protection line. Similarly, CAPU1 will activate its $1 \times 2$ switch to return the traffic signal from the protection line back to the transmission line.

Third case: Level 2 breakdown: In this particular case, both the working line $\mathrm{W} 1$ and its dedicated protection line P1 fail at the same time, as in Fig. 3(c). 
J. Computer Sci., 7 (12): 1846-1853, 2011

Table 1: Truth table of ACS for eight transmission lines (8 ONUs)

\begin{tabular}{|c|c|c|c|c|c|c|c|c|c|c|c|c|c|c|c|c|c|c|c|}
\hline Line & & & Failure & SW1 & SW2 & SW3 & SW4 & SW5 & SW6 & SW7 & SW8 & SW9 & SW10 & SW11 & SW12 & SW13 & SW14 & SW15 & SW16 \\
\hline$\overline{0}$ & 0 & 0 & No failure & 0 & $\mathrm{~d}$ & $\mathrm{~d}$ & $\mathrm{~d}$ & $\mathrm{~d}$ & $\mathrm{~d}$ & $\mathrm{~d}$ & $\mathrm{~d}$ & $\mathrm{~d}$ & $\mathrm{~d}$ & $\mathrm{~d}$ & $\mathrm{~d}$ & $\mathrm{~d}$ & $\mathrm{~d}$ & $\mathrm{~d}$ & $\mathrm{~d}$ \\
\hline 0 & 0 & 0 & W1 & 1 & 0 & $\mathrm{~d}$ & $\mathrm{~d}$ & $\mathrm{~d}$ & $\mathrm{~d}$ & $\mathrm{~d}$ & d & d & d & d & d & d & d & d & d \\
\hline 0 & 0 & 0 & W1, P1 & 1 & 1 & d & 1 & d & $\mathrm{d}$ & d & d & d & d & d & d & $\mathrm{d}$ & d & d & $\mathrm{d}$ \\
\hline 0 & 0 & 0 & $\mathrm{~W} 1, \mathrm{P} 1, \mathrm{~W} 2$ & 1 & 1 & 1 & 0 & $\mathrm{~d}$ & 1 & $\mathrm{~d}$ & d & d & d & d & d & d & d & d & d \\
\hline 0 & 0 & 1 & No failure & $\mathrm{d}$ & d & 0 & d & $\mathrm{d}$ & d & d & d & d & d & d & d & d & d & d & d \\
\hline 0 & 0 & 1 & W2 & $\mathrm{d}$ & d & 1 & 0 & $\mathrm{~d}$ & d & $\mathrm{d}$ & d & d & d & d & d & d & d & d & d \\
\hline 0 & 0 & 1 & W2, P2 & d & d & 1 & 1 & $\mathrm{~d}$ & 1 & d & d & d & d & d & d & d & d & d & d \\
\hline 0 & 0 & 1 & $\mathrm{~W} 2, \mathrm{P} 2, \mathrm{~W} 3$ & d & d & 1 & 1 & 1 & 0 & d & 1 & d & d & d & d & d & d & d & d \\
\hline 0 & 1 & 0 & No failure & d & d & d & d & 0 & d & d & d & d & d & d & d & d & d & d & d \\
\hline 0 & 1 & 0 & W3 & d & d & d & d & 1 & 0 & $\mathrm{~d}$ & d & d & d & d & d & d & $\mathrm{d}$ & d & d \\
\hline 0 & 1 & 0 & W3, P3 & d & d & d & d & 1 & 1 & d & 1 & d & d & d & d & d & d & d & d \\
\hline 0 & 1 & 0 & W3, P3, W4 & d & d & d & d & 1 & 1 & 1 & 0 & d & 1 & d & d & d & $\mathrm{d}$ & d & d \\
\hline 0 & 1 & 1 & No failure & d & d & d & d & d & d & 0 & d & d & d & d & d & d & d & d & d \\
\hline 0 & 1 & 1 & W4 & $\mathrm{d}$ & d & $\mathrm{d}$ & $\mathrm{d}$ & $\mathrm{d}$ & $\mathrm{d}$ & 1 & 0 & $\mathrm{~d}$ & $\mathrm{~d}$ & $\mathrm{~d}$ & $\mathrm{~d}$ & d & d & $\mathrm{d}$ & $\mathrm{d}$ \\
\hline 0 & 1 & 1 & W4, P4 & d & d & d & d & d & d & 1 & 1 & d & 1 & d & d & d & d & d & d \\
\hline 0 & 1 & 1 & W4, P4, W5 & $\mathrm{d}$ & $\mathrm{d}$ & $\mathrm{d}$ & $\mathrm{d}$ & $\mathrm{d}$ & $\mathrm{d}$ & 1 & 1 & 1 & 0 & d & 1 & d & $\mathrm{d}$ & $\mathrm{d}$ & $\mathrm{d}$ \\
\hline 1 & 0 & 0 & No failure & d & d & d & d & d & d & d & d & 0 & d & $\mathrm{d}$ & d & d & $\mathrm{d}$ & d & d \\
\hline 1 & 0 & 0 & W5 & d & d & $\mathrm{d}$ & d & d & d & $\mathrm{d}$ & d & 1 & 0 & $\mathrm{~d}$ & d & d & d & d & $\mathrm{d}$ \\
\hline 1 & 0 & 0 & W5, P5 & $\mathrm{d}$ & d & d & d & $\mathrm{d}$ & d & d & d & 1 & 1 & d & 1 & d & $\mathrm{d}$ & d & $\mathrm{d}$ \\
\hline 1 & 0 & 0 & W5, P5, W6 & d & d & d & d & d & d & d & d & 1 & 1 & 1 & 0 & d & 1 & d & d \\
\hline 1 & 0 & 1 & No failure & $\mathrm{d}$ & $\mathrm{d}$ & $\mathrm{d}$ & $\mathrm{d}$ & $\mathrm{d}$ & $\mathrm{d}$ & $\mathrm{d}$ & $\mathrm{d}$ & d & $\mathrm{d}$ & 0 & d & d & $\mathrm{d}$ & $\mathrm{d}$ & $\mathrm{d}$ \\
\hline 1 & 0 & 1 & W6 & d & d & d & d & d & d & d & d & d & d & 1 & 0 & d & d & d & d \\
\hline 1 & 0 & 1 & W6, P6 & d & d & d & $\mathrm{d}$ & d & $\mathrm{d}$ & d & d & d & d & 1 & 1 & d & 1 & d & $\mathrm{d}$ \\
\hline 1 & 0 & 1 & W6, P6, W7 & $\mathrm{d}$ & d & d & d & $\mathrm{d}$ & $\mathrm{d}$ & d & d & d & d & 1 & 1 & 1 & 0 & d & 1 \\
\hline 1 & 1 & 0 & No failure & d & d & d & d & d & d & d & d & d & d & d & d & 0 & d & d & d \\
\hline 1 & 1 & 0 & W7 & $\mathrm{d}$ & d & $\mathrm{d}$ & d & $\mathrm{d}$ & $\mathrm{d}$ & d & d & d & d & $\mathrm{d}$ & d & 1 & 0 & d & $\mathrm{d}$ \\
\hline 1 & 1 & 0 & W7, P7 & d & $\mathrm{d}$ & d & $\mathrm{d}$ & d & d & d & d & d & d & d & d & 1 & 1 & d & 1 \\
\hline 1 & 1 & 0 & W7, P7, W8 & d & 1 & d & d & d & $\mathrm{d}$ & $\mathrm{d}$ & d & d & $\mathrm{d}$ & $\mathrm{d}$ & d & 1 & 1 & 1 & 0 \\
\hline 1 & 1 & 1 & No failure & $\mathrm{d}$ & d & d & d & $\mathrm{d}$ & $\mathrm{d}$ & d & d & d & $\mathrm{d}$ & d & $\mathrm{d}$ & d & d & 0 & d \\
\hline 1 & 1 & 1 & W8 & $\mathrm{d}$ & d & $\mathrm{d}$ & d & $\mathrm{d}$ & d & d & d & d & d & d & $\mathrm{d}$ & d & d & 1 & 0 \\
\hline 1 & 1 & 1 & W8, P8 & $\mathrm{d}$ & 1 & d & d & d & $\mathrm{d}$ & d & d & d & $\mathrm{d}$ & d & d & d & d & 1 & 1 \\
\hline 1 & 1 & 1 & W8, P8, W1 & 1 & 0 & d & 1 & $\mathrm{~d}$ & $\mathrm{~d}$ & d & d & d & $\mathrm{d}$ & d & $\mathrm{d}$ & $\mathrm{d}$ & d & 1 & 1 \\
\hline
\end{tabular}

Table 2: Truth table of CAPU for eight transmission lines ( 8 ONUs) CAPU 1 CAPU 2 CAPU 3

CAPU 4

CAPU 5

CAPU 6

CAPU 7 CAPU 8

\begin{tabular}{|c|c|c|c|c|c|c|c|c|c|c|c|c|c|c|c|c|c|c|c|}
\hline & Line & & Failure & SW1 & SW2 & SW1 & SW2 & SW1 & SW2 & SW1 & SW2 & SW1 & SW2 & SW1 & SW2 & SW1 & SW2 & SW1 & SW2 \\
\hline 0 & 0 & 0 & No failure & 0 & $\mathrm{~d}$ & $\mathrm{~d}$ & $\mathrm{~d}$ & $\mathrm{~d}$ & $\mathrm{~d}$ & $\mathrm{~d}$ & d & $\mathrm{d}$ & $\mathrm{d}$ & $\mathrm{d}$ & $\mathrm{d}$ & $\mathrm{d}$ & $\mathrm{d}$ & $\mathrm{d}$ & $\mathrm{d}$ \\
\hline 0 & 0 & 0 & $\mathrm{~W} 1$ & 1 & 0 & $\mathrm{~d}$ & $\mathrm{~d}$ & $\mathrm{~d}$ & d & $\mathrm{d}$ & d & $\mathrm{d}$ & d & $\mathrm{d}$ & $\mathrm{d}$ & $\mathrm{d}$ & $\mathrm{d}$ & $\mathrm{d}$ & $\mathrm{d}$ \\
\hline 0 & 0 & 0 & $\mathrm{~W} 1, \mathrm{P} 1$ & 1 & 1 & d & 1 & $\mathrm{~d}$ & d & $\mathrm{d}$ & d & $\mathrm{d}$ & d & $\mathrm{d}$ & $\mathrm{d}$ & $\mathrm{d}$ & $\mathrm{d}$ & $\mathrm{d}$ & $\mathrm{d}$ \\
\hline 0 & 0 & 0 & $\mathrm{~W} 1, \mathrm{P} 1, \mathrm{~W} 2$ & 1 & 1 & 1 & 0 & $\mathrm{~d}$ & 1 & $\mathrm{~d}$ & d & $\mathrm{d}$ & d & $\mathrm{d}$ & d & $\mathrm{d}$ & $\mathrm{d}$ & $\mathrm{d}$ & d \\
\hline 0 & 0 & 1 & No failure & d & $\mathrm{d}$ & 0 & d & $\mathrm{d}$ & d & $\mathrm{d}$ & d & $\mathrm{d}$ & d & $\mathrm{d}$ & d & $\mathrm{d}$ & $\mathrm{d}$ & $\mathrm{d}$ & d \\
\hline 0 & 0 & 1 & $\mathrm{~W} 2$ & $\mathrm{~d}$ & $\mathrm{~d}$ & 1 & 0 & $\mathrm{~d}$ & d & $\mathrm{d}$ & d & $\mathrm{d}$ & d & $\mathrm{d}$ & $\mathrm{d}$ & $\mathrm{d}$ & $\mathrm{d}$ & $\mathrm{d}$ & d \\
\hline 0 & 0 & 1 & $\mathrm{~W} 2, \mathrm{P} 2$ & $\mathrm{~d}$ & $\mathrm{~d}$ & 1 & 1 & $\mathrm{~d}$ & 1 & $\mathrm{~d}$ & d & $\mathrm{d}$ & d & $\mathrm{d}$ & $\mathrm{d}$ & $\mathrm{d}$ & $\mathrm{d}$ & $\mathrm{d}$ & d \\
\hline 0 & 0 & 1 & $\mathrm{~W} 2, \mathrm{P} 2, \mathrm{~W} 3$ & $\mathrm{~d}$ & $\mathrm{~d}$ & 1 & 1 & 1 & 0 & $\mathrm{~d}$ & 1 & $\mathrm{~d}$ & d & $\mathrm{d}$ & $\mathrm{d}$ & $\mathrm{d}$ & $\mathrm{d}$ & $\mathrm{d}$ & d \\
\hline 0 & 1 & 0 & No failure & $\mathrm{d}$ & d & d & $\mathrm{d}$ & 0 & $\mathrm{~d}$ & $\mathrm{~d}$ & $\mathrm{~d}$ & $\mathrm{~d}$ & $\mathrm{~d}$ & $\mathrm{~d}$ & $\mathrm{~d}$ & $\mathrm{~d}$ & $\mathrm{~d}$ & $\mathrm{~d}$ & $\mathrm{~d}$ \\
\hline 0 & 1 & 0 & W3 & $\mathrm{d}$ & d & d & $\mathrm{d}$ & 1 & 0 & $\mathrm{~d}$ & $\mathrm{~d}$ & $\mathrm{~d}$ & $\mathrm{~d}$ & $\mathrm{~d}$ & $\mathrm{~d}$ & $\mathrm{~d}$ & $\mathrm{~d}$ & $\mathrm{~d}$ & $\mathrm{~d}$ \\
\hline 0 & 1 & 0 & W3, P3 & $\mathrm{d}$ & $\mathrm{d}$ & d & $\mathrm{d}$ & 1 & 1 & $\mathrm{~d}$ & 1 & $\mathrm{~d}$ & d & $\mathrm{d}$ & $\mathrm{d}$ & $\mathrm{d}$ & $\mathrm{d}$ & $\mathrm{d}$ & d \\
\hline 0 & 1 & 0 & $\mathrm{~W} 3, \mathrm{P} 3, \mathrm{~W} 4$ & $\mathrm{~d}$ & $\mathrm{~d}$ & d & d & 1 & 1 & 1 & 0 & $\mathrm{~d}$ & 1 & $\mathrm{~d}$ & $\mathrm{~d}$ & $\mathrm{~d}$ & $\mathrm{~d}$ & $\mathrm{~d}$ & d \\
\hline 0 & 1 & 1 & No failure & $\mathrm{d}$ & $\mathrm{d}$ & $\mathrm{d}$ & d & $\mathrm{d}$ & d & 0 & d & $\mathrm{d}$ & d & $\mathrm{d}$ & $\mathrm{d}$ & $\mathrm{d}$ & $\mathrm{d}$ & $\mathrm{d}$ & d \\
\hline 0 & 1 & 1 & W4 & $\mathrm{d}$ & $\mathrm{d}$ & $\mathrm{d}$ & $\mathrm{d}$ & $\mathrm{d}$ & d & 1 & 0 & $\mathrm{~d}$ & d & $\mathrm{d}$ & $\mathrm{d}$ & $\mathrm{d}$ & $\mathrm{d}$ & $\mathrm{d}$ & d \\
\hline 0 & 1 & 1 & $\mathrm{~W} 4, \mathrm{P} 4$ & $\mathrm{~d}$ & $\mathrm{~d}$ & $\mathrm{~d}$ & $\mathrm{~d}$ & $\mathrm{~d}$ & $\mathrm{~d}$ & 1 & 1 & $\mathrm{~d}$ & 1 & $\mathrm{~d}$ & $\mathrm{~d}$ & $\mathrm{~d}$ & $\mathrm{~d}$ & $\mathrm{~d}$ & d \\
\hline 0 & 1 & 1 & $\mathrm{~W} 4, \mathrm{P} 4, \mathrm{~W} 5$ & $\mathrm{~d}$ & d & d & $\mathrm{d}$ & $\mathrm{d}$ & d & 1 & 1 & 1 & 0 & $\mathrm{~d}$ & 1 & $\mathrm{~d}$ & $\mathrm{~d}$ & $\mathrm{~d}$ & d \\
\hline 1 & 0 & 0 & No failure & $\mathrm{d}$ & $\mathrm{d}$ & d & $\mathrm{d}$ & $\mathrm{d}$ & $\mathrm{d}$ & $\mathrm{d}$ & $\mathrm{d}$ & 0 & d & $\mathrm{d}$ & $\mathrm{d}$ & $\mathrm{d}$ & $\mathrm{d}$ & $\mathrm{d}$ & d \\
\hline 1 & 0 & 0 & W5 & $\mathrm{d}$ & $\mathrm{d}$ & $\mathrm{d}$ & $\mathrm{d}$ & $\mathrm{d}$ & d & $\mathrm{d}$ & $\mathrm{d}$ & 1 & 0 & $\mathrm{~d}$ & $\mathrm{~d}$ & $\mathrm{~d}$ & $\mathrm{~d}$ & $\mathrm{~d}$ & d \\
\hline 1 & 0 & 0 & W5, P5 & $\mathrm{d}$ & $\mathrm{d}$ & $\mathrm{d}$ & $\mathrm{d}$ & $\mathrm{d}$ & d & $\mathrm{d}$ & $\mathrm{d}$ & 1 & 1 & $\mathrm{~d}$ & 1 & $\mathrm{~d}$ & $\mathrm{~d}$ & $\mathrm{~d}$ & d \\
\hline 1 & 0 & 0 & W5, P5, W6 & $\mathrm{d}$ & $\mathrm{d}$ & $\mathrm{d}$ & $\mathrm{d}$ & $\mathrm{d}$ & d & $\mathrm{d}$ & d & 1 & 1 & 1 & 0 & $\mathrm{~d}$ & 1 & $\mathrm{~d}$ & d \\
\hline 1 & 0 & 1 & No failure & $\mathrm{d}$ & d & d & d & $\mathrm{d}$ & d & $\mathrm{d}$ & d & $\mathrm{d}$ & $\mathrm{d}$ & 0 & $\mathrm{~d}$ & $\mathrm{~d}$ & $\mathrm{~d}$ & $\mathrm{~d}$ & d \\
\hline 1 & 0 & 1 & W6 & $\mathrm{d}$ & $\mathrm{d}$ & $\mathrm{d}$ & d & $\mathrm{d}$ & d & $\mathrm{d}$ & d & $\mathrm{d}$ & d & 1 & 0 & $\mathrm{~d}$ & $\mathrm{~d}$ & $\mathrm{~d}$ & d \\
\hline 1 & 0 & 1 & W6, P6 & $\mathrm{d}$ & $\mathrm{d}$ & $\mathrm{d}$ & $\mathrm{d}$ & $\mathrm{d}$ & d & $\mathrm{d}$ & $\mathrm{d}$ & $\mathrm{d}$ & d & 1 & 1 & $\mathrm{~d}$ & 1 & $\mathrm{~d}$ & d \\
\hline 1 & 0 & 1 & W6, P6, W7 & $\mathrm{d}$ & $\mathrm{d}$ & $\mathrm{d}$ & $\mathrm{d}$ & $\mathrm{d}$ & d & $\mathrm{d}$ & $\mathrm{d}$ & $\mathrm{d}$ & d & 1 & 1 & 1 & 0 & $\mathrm{~d}$ & 1 \\
\hline 1 & 1 & 0 & No failure & $\mathrm{d}$ & $\mathrm{d}$ & $\mathrm{d}$ & $\mathrm{d}$ & $\mathrm{d}$ & d & $\mathrm{d}$ & $\mathrm{d}$ & $\mathrm{d}$ & d & $\mathrm{d}$ & $\mathrm{d}$ & 0 & $\mathrm{~d}$ & $\mathrm{~d}$ & $\mathrm{~d}$ \\
\hline 1 & 1 & 0 & W7 & $\mathrm{d}$ & d & d & $\mathrm{d}$ & $\mathrm{d}$ & d & $\mathrm{d}$ & $\mathrm{d}$ & $\mathrm{d}$ & d & $\mathrm{d}$ & $\mathrm{d}$ & 1 & 0 & $\mathrm{~d}$ & d \\
\hline 1 & 1 & 0 & W7, P7 & $\mathrm{d}$ & $\mathrm{d}$ & $\mathrm{d}$ & $\mathrm{d}$ & $\mathrm{d}$ & d & $\mathrm{d}$ & $\mathrm{d}$ & $\mathrm{d}$ & $\mathrm{d}$ & $\mathrm{d}$ & $\mathrm{d}$ & 1 & 1 & $\mathrm{~d}$ & 1 \\
\hline 1 & 1 & 0 & $\mathrm{~W} 7, \mathrm{P} 7, \mathrm{~W} 8$ & $\mathrm{~d}$ & 1 & $\mathrm{~d}$ & $\mathrm{~d}$ & $\mathrm{~d}$ & d & $\mathrm{d}$ & $\mathrm{d}$ & $\mathrm{d}$ & $\mathrm{d}$ & $\mathrm{d}$ & $\mathrm{d}$ & 1 & 1 & 1 & 0 \\
\hline 1 & 1 & 1 & No failure & $\mathrm{d}$ & $\mathrm{d}$ & $\mathrm{d}$ & $\mathrm{d}$ & $\mathrm{d}$ & d & $\mathrm{d}$ & $\mathrm{d}$ & $\mathrm{d}$ & $\mathrm{d}$ & $\mathrm{d}$ & $\mathrm{d}$ & $\mathrm{d}$ & $\mathrm{d}$ & 0 & d \\
\hline 1 & 1 & 1 & W8 & $\mathrm{d}$ & $\mathrm{d}$ & $\mathrm{d}$ & d & $\mathrm{d}$ & d & $\mathrm{d}$ & $\mathrm{d}$ & $\mathrm{d}$ & d & $\mathrm{d}$ & $\mathrm{d}$ & $\mathrm{d}$ & $\mathrm{d}$ & 1 & 0 \\
\hline 1 & 1 & 1 & W8, P8 & $\mathrm{d}$ & 1 & d & d & $\mathrm{d}$ & $\mathrm{d}$ & $\mathrm{d}$ & d & $\mathrm{d}$ & d & $\mathrm{d}$ & d & $\mathrm{d}$ & $\mathrm{d}$ & 1 & 1 \\
\hline 1 & 1 & 1 & W8, P8, W1 & 1 & 0 & d & 1 & $\mathrm{~d}$ & d & $\mathrm{d}$ & d & $\mathrm{d}$ & d & $\mathrm{d}$ & $\mathrm{d}$ & $\mathrm{d}$ & $\mathrm{d}$ & 1 & 1 \\
\hline
\end{tabular}



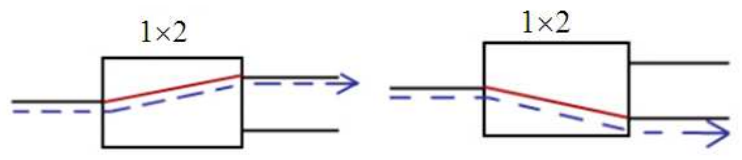

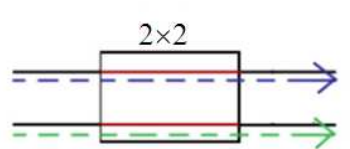

(a)

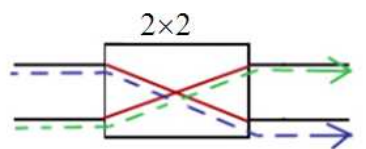

(b)
Fig. 4: Possible states for $1 \times 2$ switch and $2 \times 2$ switch, (a) Normal state and (b) Active state

The shared protection mechanism will be activated using the optical switches to divert the affected traffic signal to the nearest neighboring protection line P2.

Fourth case: level 3 breakdowns: Both the working line $\mathrm{W} 1$ and the protection line P1 fail simultaneously. The nearest neighboring working line W2 also fails whereas its protection line $\mathrm{P} 2$ is functional. In this case, L1 traffic signal will be routed to the next available protection line P3 while L2 traffic signal will be routed to its dedicated protection line P2. This case is shown in Fig. 3(d).

\section{RESULTS AND DISCUSSION}

Development of the self-restoration scheme algorithm: The type of optical switches used in the ACS system is the $n \times m$ optical switch, specifically the $1 \times 2$ switch and the $2 \times 2$ switch. There are two possible configurations, or states for these switches - the normal state (also known as the 'bar' state) and the active state (also known as the 'cross' state). These two configurations are shown in Fig. 4.

To design the $\mathrm{C}$ programs for ACS and CAPU, we need to come up with the algorithms which describe the switching configuration in general. By 'general', we mean that the same algorithm can be used for networks of different sizes regardless of the number of lines. We consider a network of eight transmission lines (eight working lines and eight protection lines). The switching configurations for various conditions of these lines (i.e., various failure combinations) are identified. The switching configurations are tabulated in the respective truth tables in Table 1-2 for ACS and CAPU.

Note that the first three digits in the truth table represent the line being tested while the rest of the digits represent the state of each switch. Working lines are denoted as $\mathrm{W} 1, \mathrm{~W} 2$ and so on; protection lines as P1, P2 and so on; and switches as SW1, SW2 and so on. A line value of ' 0 ' indicates a functional line while a ' 1 ' indicates a failed line. As for the switches, a ' 0 ' means normal state, a ' 1 ' means active state and a'd' means don't care.

A number of conclusions can be drawn from the truth tables as stated in the following:

- In case $\mathrm{W}(\mathrm{n})$ is functional but preceding neighbors $\mathrm{W}(\mathrm{n}-2), \mathrm{P}(\mathrm{n}-2)$ and $\mathrm{W}(\mathrm{n}-1)$ fail simultaneously, then the $2 \times 2$ optical switch will be activated

- In case $\mathrm{W}(\mathrm{n})$ is functional but preceding neighbors $\mathrm{W}(\mathrm{n}-1)$ and $\mathrm{P}(\mathrm{n}-1)$ fail simultaneously, then the $2 \times 2$ optical switch will be activated

- Under normal condition in which $\mathrm{W}(\mathrm{n})$ is functional, the $1 \times 2$ switch will remain in its normal state

- If W (n) fails while P (n) is still functional, then the $1 \times 2$ switch will be activated while the $2 \times 2$ switch remains in its normal state. This is to ensure that the optical signal will be routed to $\mathrm{P}(\mathrm{n})$

- If both $\mathrm{W}(\mathrm{n})$ and $\mathrm{P}(\mathrm{n})$ fail simultaneously, then both the $1 \times 2$ switch and the $2 \times 2$ switch will be activated to route the optical signal to the nearest neighboring protection line. The neighbor's $2 \times 2$ switch will be activated to carry $L(n)$ traffic signal

- If $\mathrm{W}(\mathrm{n}), \mathrm{P}(\mathrm{n})$ and the nearest neighboring working line $W(n+1)$ fail simultaneously, then both the $1 \times 2$ switch and the $2 \times 2$ switch will be activated, as well as the $1 \times 2$ switch of line $L(n+1)$. The $2 \times 2$ switch of line $L(n+2)$ will also be activated. This is to route $L(n)$ traffic signal to $P(n+2)$ and $L(n+1)$ traffic signal to $\mathrm{P}(\mathrm{n}+1)$

What will happen if $\mathrm{W}(\mathrm{n}), \mathrm{P}(\mathrm{n})$ and $\mathrm{P}(\mathrm{n}+1)$ fail simultaneously? L (n) traffic signal cannot be routed to $P(n+1)$ because of the fault. To address such a case, the switches needed to be configured in such a way that any optical signal trying to use a faulty protection line will be diverted to the next available protection line. This means that the $2 \times 2$ switch has to be in normal state ('bar' state) so that any optical signal from a neighboring line will be diverted to the next protection line instead. Table 3 summarizes the conclusions.

Based on Table 3, we can derive the flowchart which describes the switching algorithm. Figure 5 shows the flowchart which describes the switching algorithm in the ACS for the first line L1. The switching algorithm for the rest of the lines will be similar to that of $\mathrm{L} 1$.

The switching algorithm of CAPU is similar to that of ACS, except that a single CAPU controls only a pair of switches to which it is directly connected to (unlike the ACS which controls all the switches at the output of the optical splitter). 


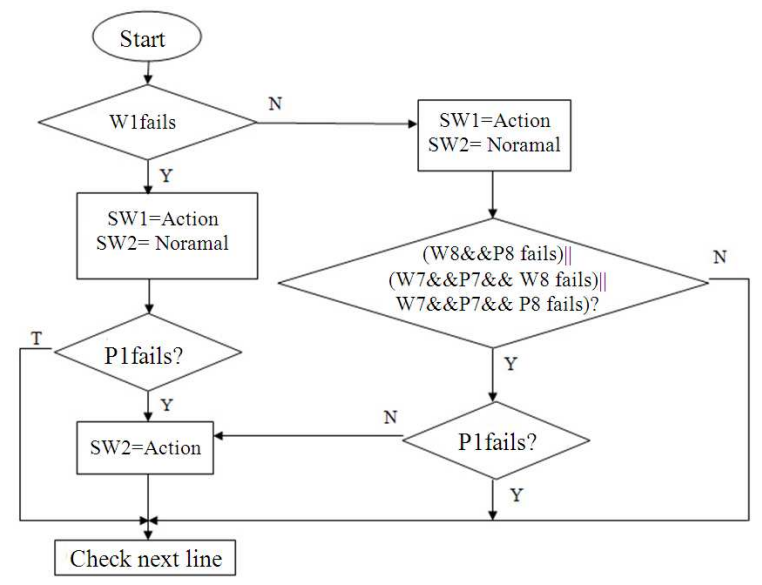

Fig. 5: Switching algorithm of ACS for the first transmission line L1

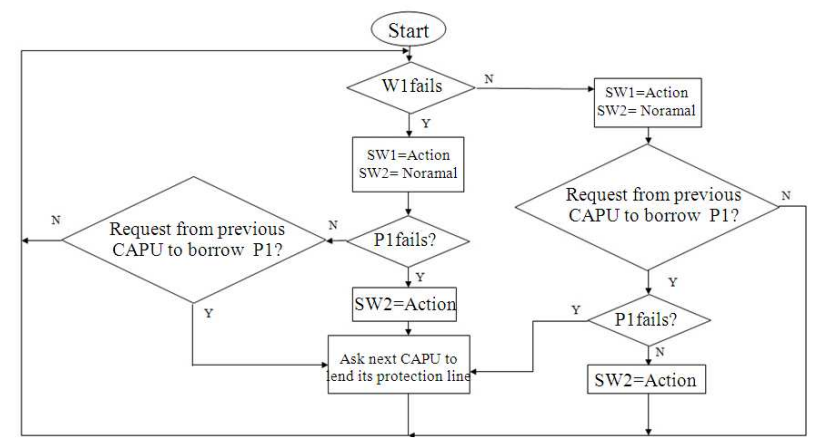

Fig. 6: Switching algorithm of CAPU1

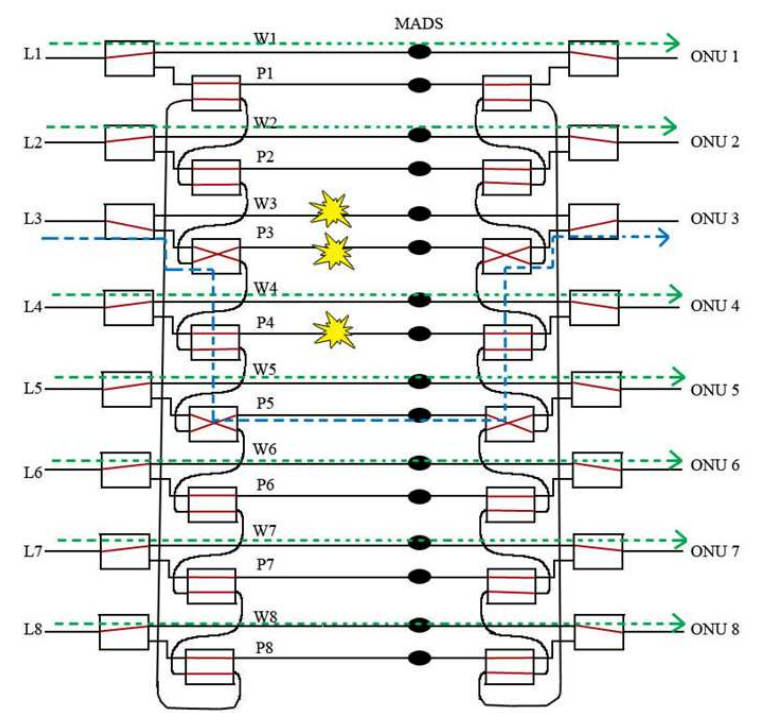

Fig. 7: Switching configuration and traffic signal route in case of failure in $\mathrm{W} 3, \mathrm{P} 3$ and $\mathrm{P} 4 \mathrm{~A}$

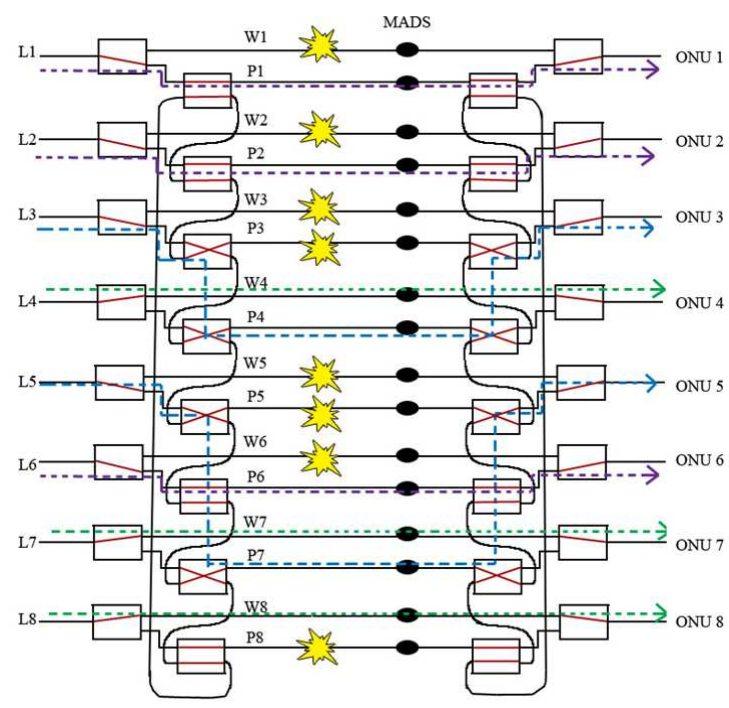

Fig. 8: Switching configuration and traffic signal route in case of failure in $\mathrm{W} 1, \mathrm{~W} 2, \mathrm{~W} 3, \mathrm{P} 3$, W5, P5, W6 dan P8

A particular CAPU has no control over any other optical switch which belongs to other CAPUs. This means, in case of a simultaneous failure on both the working line and the protection line, the CAPU needs to 'borrow' the protection line from its neighbour. To do so, the CAPU must be programmed such that it can communicate with its neighbouring CAPU. Therefore, the flowchart which describes the switching algorithm at the CAPU is a slight modification of that of the ACS. The switching algorithm flowchart of CAPU1 is shown in Fig. 6. The flowcharts of other CAPUs are similar to that of CAPU1 except for the line numbers.

Based on the flowcharts in Fig. 5 and 6, the respective $\mathrm{C}$ programs for ACS and CAPU can be written. The $\mathrm{C}$ programs will then be tested through simulation. After successful simulations, the programs may be downloaded into the respective PIC microcontrollers in the ACS and CAPU for lab testing. The programs may need to be modified and tested a few times until they can function properly.

Example failure cases and the resulting traffic signal routing: The operations of ACS and CAPU are in accordance to the $\mathrm{C}$ programs downloaded into their respective PIC microcontrollers. We will take a look at how the self-restoration scheme restores the network based on the algorithm which has been designed. The following are two example cases. 
Table 3: Summary of the ACS switching pattern

\begin{tabular}{|c|c|c|c|c|c|c|c|c|c|c|c|c|c|c|c|}
\hline \multicolumn{2}{|l|}{$\begin{array}{l}\text { Previous } \\
\text { Neighbor } \\
\text { 's (n-2) }\end{array}$} & \multicolumn{2}{|l|}{$\begin{array}{l}\text { Previous } \\
\text { neighbour's } \\
(\mathrm{n}-1)\end{array}$} & \multicolumn{2}{|l|}{$\begin{array}{l}\text { Line } \\
\text { Current } \\
\text { line }(n)\end{array}$} & \multicolumn{2}{|l|}{$\begin{array}{l}\text { Immediate } \\
\text { neighbour } \\
\text { 's }(\mathrm{n}+1)\end{array}$} & \multicolumn{2}{|l|}{$\begin{array}{l}\text { Next line } \\
(\mathrm{n}+2)\end{array}$} & \multicolumn{2}{|c|}{$\begin{array}{l}\text { Switch } \\
\text { (n) }\end{array}$} & \multicolumn{2}{|c|}{$\begin{array}{l}\text { Immediate } \\
\text { neighbor } \\
\mathrm{s}(\mathrm{n}+2)\end{array}$} & \multicolumn{2}{|c|}{$\begin{array}{l}\text { Switch } \\
\text { Next } \\
\text { neighbor } \\
\text { 's }(n+2)\end{array}$} \\
\hline $\mathrm{W}(\mathrm{n}-2)$ & $P(n-2)$ & $\mathrm{W}(\mathrm{n}-1)$ & $\mathrm{P}(\mathrm{n}-1)$ & $\mathrm{W}(\mathrm{n})$ & $\mathrm{P}(\mathrm{n})$ & $\mathrm{W}(\mathrm{n}+1)$ & $\mathrm{P}(\mathrm{n}+1)$ & $W(n+2)$ & $\mathrm{P}(\mathrm{n}+2)$ & $1 \times 2$ & $2 \times 2$ & $1 \times 2$ & $2 \times 2$ & $1 \times 2$ & $2 \times 2$ \\
\hline 1 & 1 & 1 & 0 & 0 & 0 & $\mathrm{~d}$ & $\mathrm{~d}$ & $\mathrm{~d}$ & $\mathrm{~d}$ & 0 & 1 & $\mathrm{~d}$ & $\mathrm{~d}$ & d & $\mathrm{d}$ \\
\hline 0 & 0 & 1 & 1 & 0 & 0 & $\mathrm{~d}$ & $\mathrm{~d}$ & $\mathrm{~d}$ & $\mathrm{~d}$ & 0 & 1 & $\mathrm{~d}$ & $\mathrm{~d}$ & $\mathrm{~d}$ & $\mathrm{~d}$ \\
\hline 0 & 0 & 0 & 0 & 0 & 0 & $\mathrm{~d}$ & $\mathrm{~d}$ & $\mathrm{~d}$ & $\mathrm{~d}$ & 0 & 0 & $\mathrm{~d}$ & $\mathrm{~d}$ & $\mathrm{~d}$ & $\mathrm{~d}$ \\
\hline 0 & 0 & 0 & 0 & 1 & 0 & $\mathrm{~d}$ & $\mathrm{~d}$ & $\mathrm{~d}$ & $\mathrm{~d}$ & 1 & 0 & $\mathrm{~d}$ & $\mathrm{~d}$ & $\mathrm{~d}$ & $\mathrm{~d}$ \\
\hline 0 & 0 & 0 & 0 & 1 & 1 & 0 & 0 & $\mathrm{~d}$ & d & 1 & 1 & 0 & 1 & $\mathrm{~d}$ & $\mathrm{~d}$ \\
\hline 0 & 0 & 0 & 0 & 1 & 1 & 1 & 0 & 0 & 0 & 1 & 1 & 1 & 0 & 0 & 1 \\
\hline 0 & 0 & 0 & 0 & 1 & 1 & 0 & 1 & 0 & 0 & 1 & 1 & 0 & 0 & 0 & 1 \\
\hline
\end{tabular}

First example case: failure at W3, P3 and P4: Figure 7 shows an example case where W3, P3 and P4 fail simultaneously. Since both the working line W3 and its protection line P3 fail at the same time, then both SW5 and SW6 of line L3 will be activated by the ACS in order to route L3 optical signal to its neighboring protection line. Such is the switching configuration dictated by the algorithm of the $\mathrm{C}$ program. The corresponding pair of switches in CAPU3 will also be activated in the same manner. The activation of SW5 and SW6 will cause the optical signal to be diverted to the neighboring protection line $\mathrm{P} 4$. However, there is a fault occurring in P4 and hence the line cannot be used. Thus, switch SW8 will remain in normal state so that any optical signal routed to $\mathrm{P} 4$ will be diverted to the next protection line. As a result, L3 traffic signal is routed to P5.

Second example case: failure at various lines: When several faults occur at various lines, each MADS informs ACS and all CAPUs of the current line conditions. As programmed, ACS and CAPU will configure their switches to restore the network. An example of such a case is shown in Fig. 8.

In case of failure of the working line, the traffic signal will be routed to its dedicated protection line, for example from W1-P1 and from W2-P2. If the dedicated protection line also fails, as in $\mathrm{W} 3$ and $\mathrm{P} 3$, then the signal will be routed to the nearest neighboring protection line, in this case P4. In case of failure in three consecutive lines (i.e., two working lines and a protection line) then the next available protection line will be used. An example of such case is the simultaneous failures of W5, P5 and W6, where L5 traffic signal is routed to P7 while L6 traffic signal is routed to P6. Finally, if the protection line fails while the working line is functional, no harm is done to communications through the line. For example, the failure of P8 alone does not affect L8 traffic signal since W8 can be used to carry the signal.

\section{CONCLUSION}

The study discussed the development of respective algorithms for ACS and CAPU to automatically perform FTTH-PON self-restoration scheme. Two separate $\mathrm{C}$ programs will be written based on these algorithms, which will be downloaded into the respective PIC microcontrollers in ACS and CAPU. The automatic self-restoration scheme provides network protection in the downstream region through the routing of traffic signals from affected lines to backup lines. The signal routing is accomplished through the configurations of optical switches which are controlled by ACS and CAPU. The designed C programs dictate how ACS and CAPU determine the configuration of their optical switches.

\section{REFERENCES}

Ab-Rahman, M.S., B.C. Ng, A. Premadi and K. Jumari, 2009a. Transmission surveillance and selfrestoration against fibre fault for time division multiplexing using passive optical network. IET Commun., 3: 1896-1906. DOI: 10.1049/ietcom.2009.0017

Ab-Rahman, M.S., S.A.C. Aziz and K. Jumari, 2009b. Protection for an immediate split structure of treebased epon architecture-ideal condition analysis. Am. J. Eng. Appl. Sci., 2: 372-380. DOI: 10.3844/ajeassp.2009.372.380

Ab-Rahman, M.S., S.R. Hassan and K. Jumari, 2009c. Customer access protection unit (CAPU) performing auto-restoration in line with access control system (ACS) for FTTH customer's network. Proceeding of the International Conference on Space Science and Communication, Oct. 26-27, IEEE Xplore, Negeri Sembilan, pp: 7477. DOI: 10.1109/ICONSPACE.2009.5352665

Aziz, S.A.C., M.S. Ab-Rahman and K. Jumari, 2009. Customer Access Protection Unit for Survivable FTTH Network. Proceeding of the International Conference on Space Science and Communication, Oct. 26-27, pp: 71-73. DOI: 10.1109/ICONSPACE.2009.5352668 
Fijnvandraat, M. and H. Bouwman, 2006. Flexibility and broadband evolution. Telecomm. Policy, 30: 424-444. DOI: 10.1016/j.telpol.2006.05.002

Hutcheson, L., 2008. FTTx: Current status and the future. Commun. Mag. IEEE, 46: 90-95. DOI: 10.1109/MCOM.2008.4557048

Lee, K., S.B. Kang, D.S. Lim, H.K. Lee and W.V. Sorin, 2006. Fiber link loss monitoring scheme in bidirectional WDM transmission using ASEinjected FP-LD. IEEE Photon. Tech. Lett., 18: 523525. DOI: 10.1109/LPT.2005.863991

Ng, B., M.S. Ab-Rahman and A. Premadi, 2010. Development of monitoring system for ftth-pon using combined acs and SANTAD. Int. J. Commun. Syst., 23: 429-446. DOI: $10.1002 /$ dac. 1078

Nadarajah, N., E.Wong and A. Nirmalathas, 2006. Automatic protection switching and lan emulation in passive optical networks. Elect. Lett., 42: 171173. 10.1049/el: 20063934

Premadi, A., M.S.A. Rahman, M.N.M. Saupe and K. Jumari, 2009a. Access control system: Monitoring tool for fiber to the home passive optical network. World Acad. Sci. Eng. Technol., 50: 45-50.
Premadi, A., M.S. Ab-Rahman, M.N.B. Saupe and K. Jumari, 2009b. Application of PIC microcontroller for online monitoring and fiber fault identification. Proceeding of the International Conference on Electrical Engineering and Informatics, Aug. 5-7, IEEE Xplore Press, Selangor, pp: 463-467. DOI: 10.1109/ICEEI.2009.5254693

Yeh, C.H., C.S. Lee and S. Chi, 2008. Self-protecting dual-ring-architecture in time-sharing passive optical network to prevent the occurrence of fiber failure. Optics Commun., 281: 1534-1537. DOI: 10.1016/j.optcom.2007.11.052

Yuksel, K., V. Moeyaert, M. Wuilpart and P. Megret, 2008. Optical layer monitoring in Passive Optical Networks (PONs): A review. Proceedings of the International Conference on Transparent Optical Networks, June 22-26, IEEE Xplore Press, Athens, pp: 92-98. DOI: 10.1109/ICTON.2008.4598379 